\title{
Physical symptoms in outpatients with psychiatric disorders consulting the general internal medicine division at a Japanese university hospital
}

This article was published in the following Dove Press journal:

International Journal of General Medicine

13 August 2015

Number of times this article has been viewed

\author{
Yukiko Ishikawa' \\ Taro Takeshima ${ }^{1,2}$ \\ Junichi Mise' \\ Shizukiyo Ishikawa' \\ Masami Matsumura' \\ 'Division of General Medicine, \\ ${ }^{2}$ Division of Community and Family \\ Medicine, Center for Community \\ Medicine, Jichi Medical University \\ School of Medicine, Shimotsuke, \\ Tochigi, Japan
}

Purpose: General practitioners have an important role in diagnosing a variety of patients, including psychiatric patients with complicated symptoms. We evaluated the relationship between physical symptoms and psychiatric disorders in general internal medicine (GIM) outpatients in a Japanese university hospital.

Materials and methods: We coded the symptoms and diagnoses of outpatients from medical documents using the International Classification of Primary Care, second edition (ICPC-2). The participants were new outpatients who consulted the GIM outpatient division at Jichi Medical University Hospital in Tochigi, Japan from January-June, 2012. We reviewed all medical documents and noted symptoms and diagnoses. These were coded using ICPC-2.

Results: A total of 1,194 participants were evaluated, 148 (12.4\%) of whom were diagnosed as having psychiatric disorders. The prevalence of depression, anxiety disorder, and somatization was $19.6 \%$ (number $[\mathrm{n}]=29), 14.9 \%(\mathrm{n}=22)$, and $14.2 \%(\mathrm{n}=21)$, respectively, among the participants with psychiatric disorders. The presence of several particular symptoms was associated with having a psychiatric disorder as compared with the absence of these symptoms after adjusting for sex, age, and the presence of multiple symptoms (odds ratio [OR] $=4.98[95 \%$ confidence interval $\{\mathrm{CI}\}$ : 1.66-14.89] for palpitation; OR $=4.36$ [95\% CI: 2.05-9.39] for dyspnea; OR $=3.46$ [95\% CI: $1.43-8.36]$ for tiredness; and OR $=2.99$ [95\% CI: 1.75-5.13] for headache).

Conclusion: Not only the psychiatric symptoms, but also some physical symptoms, were associated with psychiatric disorders in GIM outpatients at our university hospital. These results may be of help to general practitioners in appropriately approaching and managing patients with psychiatric disorders.

Keywords: physical symptoms, psychiatric disorders, university hospital, International Classification of Primary Care 2nd edition

\section{Introduction}

Improvements in the health care system have contributed to an increasingly aged population and a higher prevalence of various chronic disorders and multimorbidity. ${ }^{1,2}$ One study in Australia showed that multimorbidity was commonly associated with psychiatric problems. ${ }^{3} \mathrm{Up}$ to one-third of patients in a primary care setting complained of medically unexplained symptoms (MUS). ${ }^{4}$ Agüera et $\mathrm{al}^{5}$ reported that the prevalence of undiagnosed mood disorders in patients with unexplained chronic pain in primary care was $80.4 \%$. It has been reported that a number of physical symptoms are associated with psychiatric disorders, and that some particular symptoms are predictive of psychiatric disorders. ${ }^{6-8}$

Patients with somatic symptoms caused by psychiatric disorders tend to frequently change doctors without referral, seek unnecessary examinations, receive treatment without
Correspondence: Yukiko Ishikawa Division of General Medicine, Jichi Medical University Hospital, Yakushiji 33II-I, Shimotsuke, Tochigi 329-0498, Japan

Tel +8I 285587394

Fax +8I 285440628

Email yuishi@jichi.ac.jp 
consulting psychiatrists, or visit a tertiary hospital directly. ${ }^{9}$ Failure to recognize the psychiatric disorder has been associated with undertreatment, greater impairment, and longer duration of illness. ${ }^{710}$ The International Classification of Primary Care, second edition (ICPC-2) allows for the coding of reasons for encounters in an episode of care, applied to both physical and mental issues, specifically for use in primary care. ${ }^{11-13}$

The EPIsode CONstructor (EPICON), which is a useful computerized system for grouping diagnoses and estimating morbidity from electronic medical records, has already been established in northwestern Europe, Sweden, Denmark, and the Netherlands. ${ }^{14,15}$ Because such a system has yet to be developed in Japan, ICPC coding has been performed by checking all pertinent medical documents despite the cost in terms of time and effort involved. Even though a large-scale study could not be conducted, there have been several reports that reveal the frequency of reasons for encounters in some primary care settings in Japan. ${ }^{16,17}$ ICPC-2 was translated into Japanese and its broad use was attempted by the ICPC working team of the Japan Primary Care Association, because ICPC coding was thought to be useful for understanding the medical needs in the primary care setting. The role of general practitioners (GPs) in mental health care has been increasing because of the rising burden of mental disorders. ${ }^{18-20}$ GPs are expected to become gatekeepers for patients with psychiatric disorders whose somatic symptoms have not been diagnosed as mental problems. ${ }^{21}$ Yamada et $\mathrm{al}^{17}$ assessed the accuracy of a family physician's diagnosis of depression and alcoholism. Integrated care of mental health by GPs was reported to improve patient satisfaction. ${ }^{22}$

Taking these changes in mental health care into consideration, evidence useful in the prediction of mental disorders would be very welcome and research should also be advanced in Japan, which is a special setting characterized by certain features, such as easy access to any medical provider.

This study was undertaken to clarify the relationship between symptoms and psychiatric disorders in a general internal medicine (GIM) outpatient division in a university hospital using ICPC-2 to code the symptoms and diagnoses of outpatients.

\section{Materials and methods}

\section{Study design}

An observational design was employed.

\section{Patients}

The present participants comprised new outpatients who consulted the GIM division. The number of outpatients in the GIM division was 1,541 from January-June 2012. We identified the 1,209 participants who complained of new symptoms after excluding any returning patients who consulted us for the same symptom as in the previous month. We excluded the patients who came only to receive prescriptions (number $[n]=6$ ), family consultation $(n=6)$, examination only $(n=1)$, and medical certification only $(n=1)$. The final number of eligible participants was 1,194 for this study (Figure 1).

\section{Setting}

The Jichi Medical University Hospital (Tochigi, Japan) has 1,132 beds and provides not only advanced medical care, but also primary care for the local community. The GIM division has 16 beds and manages both inpatients and outpatients. It diagnoses and treats patients with common disorders, multiple health problems, or symptoms of unknown origin. We treat patients both with and without referrals. While the percentage of patients with referral for the entire hospital is $60 \%$, that for our division is $30 \%$. Japan has a public health insurance system covering most of the population, allowing them to consult all types of health care providers and to consult most physicians without referral. ${ }^{9}$

The outpatients without referral are guided to make a brief stop at the information counter where a doctor recommends the most appropriate department or division for their consultation. Those who need to see generalists are recommended to visit the division of GIM. Some of these patients often have fears regarding their own symptoms because no doctors approached or managed their health problems of unknown origin. Therefore, they started to insist on obtain-

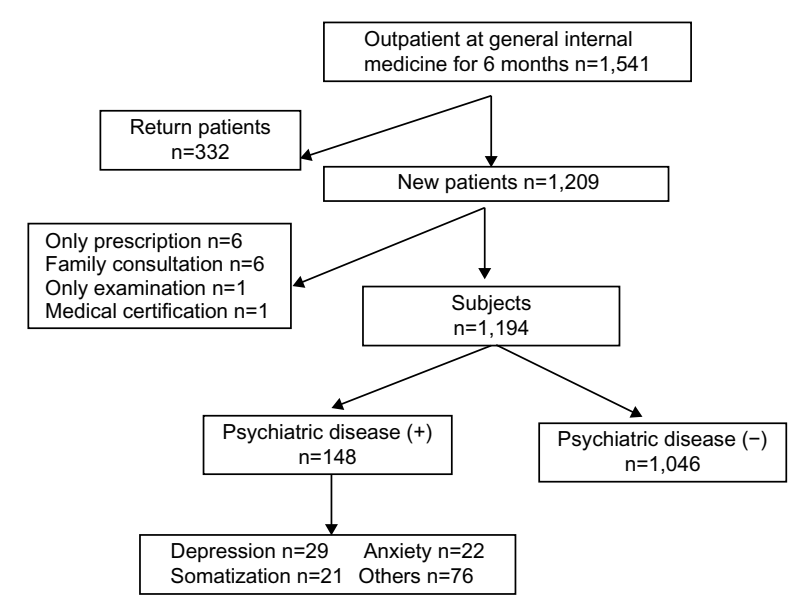

Figure I Flowchart of participants and the number of categories of psychiatric disorders diagnosed by general practitioners.

Note: $(+)$ positive; $(-)$ negative.

Abbreviation: $n$, number. 
ing a guaranteed high level of service. The role of GIM is thought to include the management of mental problems that cause physical symptoms.

\section{Measurements}

We evaluated symptoms and diagnoses from the patients' medical records and coded them according to the ICPC $-2 .{ }^{23}$ The ICPC-2 code consisted of 17 chapters (A-Z) and seven components, including symptoms and diagnoses. Six physicians who practice in the outpatient clinic of the GIM division attended a tutorial about coding by ICPC-2. In the tutorial, they were informed of the methods extracting symptoms and diagnosis from medical documents and coding them in ICPC. After the tutorial, they coded the medical documents of the participants. Two investigators later checked all coded data sheets for accuracy. If a discrepancy in the coding between investigators was found, one author (JM), who is a member of the ICPC working team of the Japan Primary Care Association, provided the final classification code. If the patients had multiple symptoms, we selected the symptom noted first by a physician and coded it for the analysis. We gave a final diagnosis and coded it after we checked the current medical history and the following medical documents as well. If the participants had multiple diagnoses, we noted up to four diagnoses. Those diagnoses and the coding of psychiatric disorders were not obtained by psychological tests, but by clinical diagnoses by the GPs or the result of psychiatric consultation. If the participants had at least one psychiatric diagnosis, they were defined as having a psychiatric disorder regardless of the existence of other diagnoses.

\section{Data analysis}

A comparison of various characteristics between the groups with and without a psychiatric disorder was performed using the chi-squared test for nominal variables and the Student's $t$-test for continuous variables. The odds ratio (OR) and 95\% confidence intervals (CI) were calculated by multivariable logistic regression to evaluate the risk of having a psychiatric disorder for the participants with each symptom. We analyzed the association between common somatic symptoms and psychiatric disorders using multivariable logistic regression analysis adjusted by sex, age, and the presence of multiple symptoms. The statistical analyses were performed using the SPSS version 19.0 (IBM Corporation, Armonk, NY, USA) computer software package. A probability value of $P<0.05$ was considered statistically significant.

\section{Ethics}

The institutional review board of Jichi Medical University approved this study.

\section{Results}

The participants' ages ranged from 15 to 92 years (mean age: $50.5 \pm 19.3$ years) and $686(57.5 \%)$ of the 1,209 participants were men. Of all the participants, 245 (20.5\%) were referred by other clinics. A total of 148 (12.1\%) were diagnosed as having psychiatric disorders. Table 1 shows the characteristics of the study participants between those with and without psychiatric disorders. Those with psychiatric disorders were younger than those without them. The number of symptoms in those with psychiatric disorders was greater than that in those without them, and the proportion of the participants with two or more symptoms among those with psychiatric disorders was greater than among those without the disorders. There were 148 participants with psychiatric disorders (Figure 1). Of those, the most frequent diagnoses were P76 (depression; 19.6\%), P99 (psychological disorders, other; 16.2\%), P74 (anxiety disorder; 14.9\%), P75 (somatization; 14.2\%), and P06 (sleep disturbance; 11.5\%). The P99 was defined to include an unspecified status that was attributed to psychosomatic factors. Table 2 shows the common symptoms of the participants with psychiatric disorders.

Table 3 shows the risk of having a psychiatric disorder for those participants with common somatic symptoms. The participants with psychiatric symptoms showed obvious sleep disturbance (OR =73.99; 95\% CI: 8.97-609.96). The presence of particular physical symptoms was associated with having a psychiatric disorder, as compared with their absence after adjusting for sex, age, and the presence of multiple symptoms $(\mathrm{OR}=4.98$ [95\% CI: 1.66-14.89] for

Table I Comparison of the characteristics between those with present or absent psychiatric disorders

\begin{tabular}{|c|c|c|c|}
\hline $\begin{array}{l}\text { Psychiatric } \\
\text { disorder }\end{array}$ & $\begin{array}{l}\text { Present } \\
(n=\mid 48 ; 12.4 \%)\end{array}$ & $\begin{array}{l}\text { Absent } \\
(n=I, 046 ; 87.6 \%)\end{array}$ & $P$ \\
\hline Mean age & $46.1 \pm 18.0$ & $51.1 \pm 19.2$ & $0.004 * *$ \\
\hline Men & $89(60.1 \%)$ & 597 (57.1\%) & $0.48 I^{*}$ \\
\hline $\begin{array}{l}\text { Mean number } \\
\text { of symptoms }\end{array}$ & $2.33 \pm 1.24$ & $1.88 \pm 1.10$ & $<0.00 I^{*}$ \\
\hline $\begin{array}{l}\text { Number of } \\
\text { symptoms, } \geq 2\end{array}$ & 104 (70.3\%) & $533(51.0 \%)$ & $<0.00 I^{*}$ \\
\hline $\begin{array}{l}\text { Referral from a } \\
\text { family physician }\end{array}$ & 37 (25.0\%) & 208 (19.9\%) & 0.149 \\
\hline
\end{tabular}

Notes: Data are shown as the mean \pm standard deviation or percentage. The comparison among subjects classified as present or absent of psychiatric disease was performed by a *chi-squared test or an **independent $t$-test.

Abbreviation: $\mathrm{n}$, number. 
Table 2 Prevalence of each symptom with psychiatric disorders

\begin{tabular}{llll}
\hline ICPC & Symptom & n & $\%$ \\
\hline N0I & Headache & 22 & 14.9 \\
R02 & Dyspnea & 12 & 8.1 \\
NI7 & Dizziness & 10 & 6.8 \\
A04 & Tiredness & 8 & 5.4 \\
P06 & Sleep disturbance & 8 & 5.4 \\
K04 & Palpitation & 6 & 4.1 \\
N06 & Sensation disturbance & 6 & 4.1 \\
P29 & Psychological symptoms, other & 6 & 4.1 \\
A03 & Fever & 5 & 3.4 \\
AlI & Nonspecific chest pain & 5 & 3.4 \\
\hline
\end{tabular}

Abbreviations: ICPC, International Classification of Primary Care; n, number.

palpitation; OR $=4.36$ [95\% CI: 2.05-9.39] for dyspnea; $\mathrm{OR}=3.46$ [95\% CI: $1.43-8.36]$ for tiredness; and $\mathrm{OR}=2.99$ [95\% CI: 1.75-5.13] for headache).

\section{Discussion}

In our study, participants in whom palpitation, dyspnea, tiredness, or headache was identified were more likely to have psychiatric disorders. Physical symptoms of the participants with psychiatric disorders turned out to be common.

Various patient factors might explain why many patients with a psychiatric disorder complained of only physical symptoms. First, they may not be good at expressing their own mental condition. ${ }^{24}$ Additionally, they may want to be reassured by consulting a health service and being examined repeatedly, because of a fear that they are suffering from a serious physical illness. ${ }^{25}$ Physician factors might include an inappropriate patient-physician relationship that may not provide an opportunity for patients to express their psychiatric symptoms to physicians.

GPs at university hospitals, who often encounter such difficult patients, should be competent to exclude critical illness and determine the possibility of psychiatric disorders. ${ }^{26-28}$ Rasmussen et $\mathrm{al}^{7}$ reported that headache, chest pain, dizziness, sleep disturbance, dyspnea, and tiredness were significantly related to the presence of psychiatric disorders in rural primary care adults. These symptoms were similar to those found in our study with the exception of palpitation. Barsky et $\mathrm{al}^{29}$ reported that $29 \%$ of 82 outpatients who complained of palpitation without any abnormalities on ambulatory electrocardiographic monitoring had a current psychiatric disorder, and $83 \%$ of these patients had major depression or panic disorder. In clinical practice, dyspnea is frequently derived from critical conditions - ie, ischemic heart disease, cardiac failure, ventricular arrhythmia, atrial fibrillation, atrial flutter, pulmonary embolism, other pulmonary disorders, or hematological or metabolic disorders. Han et $\mathrm{a}^{30}$ reported that the presence of the urge to breathe, affective dyspnea, anxiety, and tingling pointed to a diagnosis of MUS, whereas the reporting of wheezing, cough and sputum, and palpitation were more likely to be due to cardiopulmonary diseases causing dyspnea.

One limitation of our study was that the number of participants was relatively small for identifying the symptoms predictive of psychiatric disorders. Coding the ICPC from each medical document was a heavy burden for the researchers. The lack of an automatic conversion system for coding the ICPC from the medical records made it difficult to collect sufficient data. Another limitation was that psychiatric disorders might be underdiagnosed in the participants. The prevalence of psychiatric disorders was $12.1 \%$ in our study, while it was $22.6 \%$ in Rasmussen's study using the primary care evaluation of mental disorders (PRIME-MD) in all the outpatient primary care adults. ${ }^{7}$ Olivera et $\mathrm{al}^{31}$ reported that the prevalence of psychiatric disorders was $46.1 \%$ in the elderly, as determined by psychogeriatric screening instruments. The proportion of participants with psychiatric disorders in our study might have been underestimated because the diagnoses of psychiatric disease were based on clinical interviews alone.

\section{Conclusion}

In conclusion, not only psychiatric symptoms, but also palpitation, dyspnea, tiredness, and headache, were associated

Table 3 Risk of having psychiatric disorders among the subjects with common somatic symptoms

\begin{tabular}{|c|c|c|c|c|c|c|c|c|c|}
\hline \multirow[t]{3}{*}{ ICPC } & \multirow[t]{3}{*}{ Symptom } & \multicolumn{4}{|c|}{ Psychiatric disorder } & \multicolumn{2}{|c|}{ Nonadjusted } & \multicolumn{2}{|c|}{ Adjusted } \\
\hline & & \multicolumn{2}{|c|}{ Present } & \multicolumn{2}{|c|}{ Absent } & \multirow[t]{2}{*}{ OR } & \multirow[t]{2}{*}{$95 \% \mathrm{Cl}$} & \multirow[t]{2}{*}{ OR } & \multirow[t]{2}{*}{$95 \% \mathrm{Cl}$} \\
\hline & & $\mathbf{n}$ & $\%$ & $\mathbf{n}$ & $\%$ & & & & \\
\hline NOI & Headache & 22 & 14.9 & 56 & 5.4 & 3.09 & $1.82-5.23$ & 2.99 & $1.75-5.13$ \\
\hline R02 & Dyspnea & 12 & 8.1 & 20 & 1.9 & 4.53 & $2.16-9.47$ & 4.36 & $2.05-9.3$ \\
\hline NI7 & Dizziness & 10 & 6.8 & 47 & 4.5 & 1.54 & $0.76-3.12$ & 1.7 & $0.82-3.45$ \\
\hline A04 & Tiredness & 8 & 5.4 & 16 & 1.5 & 3.68 & $1.55-8.75$ & 3.46 & $1.43-8.36$ \\
\hline P06 & Sleep disturbance & 8 & 5.4 & I & 0.1 & 59.71 & $7.4 I-48 I .01$ & 73.99 & $8.97-609.96$ \\
\hline K04 & Palpitation & 6 & 4.1 & 8 & 0.8 & 5.48 & $1.88-16.03$ & 4.98 & $1.66-14.89$ \\
\hline
\end{tabular}

Note: Adjusted OR, $95 \% \mathrm{Cls}$ were calculated after adjusting for sex, age, and the presence of multiple symptoms.

Abbreviations: ICPC, International Classification of Primary Care; n, number; OR, odds ratio; $\mathrm{Cl}$, confidence interval. 
with the physical symptoms of psychiatric disorders in outpatients consulting the GIM division at one Japanese university hospital. The diagnostic accuracy of psychiatric disorders in patients with MUS could lead to appropriate treatment and health care cost reduction. These results may help GPs to diagnose and manage patients with psychiatric disorders appropriately.

\section{Acknowledgments}

Ayako Noda, Takashi Sekiguchi, Takeshi Tanabe, Reiko Yamamoto, Shinichi Uchida, and Hidehiko Kamiyama contributed to the acquisition of data. We thank John Gelblum for his critical reading of the manuscript.

\section{Author contributions}

YI contributed to the conception and design of the study, the acquisition of data, the analysis and interpretation of data, and the writing and revision of the manuscript; TT, JM, SI, and MM contributed to the conception and design of the study, interpretation of data, and the writing and revision of the manuscript. All authors approved the final version of the manuscript.

\section{Disclosure}

The authors report no conflicts of interest in this work.

\section{References}

1. Rizza A, Kaplan V, Senn O, Rosemann T, Bhend H, Tandjung R; FIRE study group. Age- and gender-related prevalence of multimorbidity in primary care: the Swiss FIRE project. BMC Fam Pract. 2012;13:113.

2. Barnett K, Mercer SW, Norbury M, Watt G, Wyke S, Guthrie B. Epidemiology of multimorbidity and implications for health care, research, and medical education: a cross-sectional study. Lancet. 2012; 380(9836):37-43.

3. Britt HC, Harrison CM, Miller GC, Knox SA. Prevalence and patterns of multimorbidity in Australia. Med J Aust. 2008;189(2):72-77.

4. Kroenke K, Price RK. Symptoms in the community. Prevalence, classification, and psychiatric comorbidity. Arch Intern Med. 1993;153(21): 2474-2480.

5. Agüera L, Failde I, Cervilla JA, Díaz-Fernández P, Mico JA. Medically unexplained pain complaints are associated with underlying unrecognized mood disorders in primary care. BMC Fam Pract. 2010;11:17.

6. Kroenke K, Spitzer RL, Williams JB, et al. Physical symptoms in primary care. Predictors of psychiatric disorders and functional impairment. Arch Fam Med. 1994;3(9):774-779.

7. Rasmussen NH, Bernard ME, Harmsen WS. Physical symptoms that predict psychiatric disorders in rural primary care adults. J Eval Clin Pract. 2008;14(3):399-406.

8. Jackson JL, Houston JS, Hanling SR, Terhaar KA, Yun JS. Clinical predictors of mental disorders among medical outpatients. Arch Intern Med. 2001;161(6):875-879.

9. Guo Y, Kuroki T, Yamashiro S, Koizumi S. Illness behaviour and patient satisfaction as correlates of self-referral in Japan. Fam Pract. 2002;19(4):326-332.

10. Ormel J, Koeter MW, van den Brink W, van de Willige G. Recognition, management, and course of anxiety and depression in general practice. Arch Gen Psychiatry. 1991;48(8):700-706.
11. Soler JK, Okkes I, Wood M, Lamberts H. The coming of age of ICPC: celebrating the 21 st birthday of the International Classification of Primary Care. Fam Pract. 2008;25(4):312-317.

12. Rosendal M, Vedsted P, Christensen KS, Moth G. Psychological and social problems in primary care patients - general practitioners' assessment and classification. Scand J Prim Health Care. 2013;31(1): 43-49.

13. Gask L, Klinkman M, Fortes S, Dowrick C. Capturing complexity: the case for a new classification system for mental disorders in primary care. Eur Psychiatry. 2008;23(7):469-476.

14. Biermans MC, Elbers GH, Verheij RA, Jan van der Veen W, Zielhuis GA, Robbé PF. External validation of EPICON: a grouping system for estimating morbidity rates using electronic medical records. J Am Med Inform Assoc. 2008;15(6):770-775.

15. Biermans MC, de Bakker DH, Verheij RA, Gravestein JV, van der Linden MW, Robbé PF. Development of a case-based system for grouping diagnoses in general practice. Int J Med Inform. 2008;77(7):431-439.

16. Takeshima T, Kumada M, Mise J, et al. Reasons for encounter and diagnoses of new outpatients at a small community hospital in Japan: an observational study. Int J Gen Med. 2014;7:259-269.

17. Yamada K, Maeno T, Waza K, Sato T. Under-diagnosis of alcoholrelated problems and depression in a family practice in Japan. Asia Pac Fam Med. 2008;7(1):3.

18. Murray CJ, Vos T, Lozano R, et al. Disability-adjusted life years (DALYs) for 291 diseases and injuries in 21 regions, 1990-2010: a systematic analysis for the Global Burden of Disease Study 2010. Lancet. 2012;380(9859):2197-2223.

19. Olfson M, Kroenke K, Wang S, Blanco C. Trends in office-based mental health care provided by psychiatrists and primary care physicians J Clin Psychiatry. 2014;75(3):247-253.

20. Fortin M, Lapointe L, Hudon C, Vanasse A, Ntetu AL, Maltais D. Multimorbidity and quality of life in primary care: a systematic review. Health Qual Life Outcomes. 2004;2:51.

21. Oiesvold T, Sandlund M, Hansson L, et al. Factors associated with referral to psychiatric care by general practitioners compared with selfreferrals. Psychol Med. 1998;28(2):427-436.

22. Khadivi R, Shakeri M, Ghobadi S. The efficiency of mental health integration in primary health care: a ten-year Study. Int J Prev Med. 2012;3(Suppl 1):S139-S145.

23. Hiroshi S, Nobusuke F, Masaaki Y. International Classification of Primary Care, second edition (ICPC-2). Tokyo, Japan: Japan Primary Care Association; 2002:216.

24. Nemiah JC. A reconsideration of psychological specificity in psychosomatic disorders. Psychother Psychosom. 1982;38(1):39-45.

25. Burton C, McGorm K, Richardson G, Weller D, Sharpe M. Healthcare costs incurred by patients repeatedly referred to secondary medical care with medically unexplained symptoms: a cost of illness study. J Psychosom Res. 2012;72(3):242-247.

26. Smith RC, Lyles JS, Gardiner JC, et al. Primary care clinicians treat patients with medically unexplained symptoms: a randomized controlled trial. J Gen Intern Med. 2006;21(7):671-677.

27. Little P, Everitt H, Williamson I, et al. Observational study of effect of patient centredness and positive approach on outcomes of general practice consultations. BMJ. 2001;323(7318):908-911.

28. Cannarella Lorenzetti R, Jacques CH, Donovan C, Cottrell S, Buck J. Managing difficult encounters: understanding physician, patient, and situational factors. Am Fam Physician. 2013;87(6):419-425.

29. Barsky AJ, Delamater BA, Clancy SA, Antman EM, Ahern DK. Somatized psychiatric disorder presenting as palpitations. Arch Intern Med. 1996;156(10):1102-1108.

30. Han J, Zhu Y, Li S, et al. The language of medically unexplained dyspnea. Chest. 2008;133(4):961-968.

31. Olivera J, Benabarre S, Lorente T, et al. Prevalence of psychiatric symptoms and mental disorders detected in primary care in an elderly Spanish population. The PSICOTARD Study: preliminary findings. Int J Geriatr Psychiatry. 2008;23(9):915-921. 


\section{Publish your work in this journal}

The International Journal of General Medicine is an international, peer-reviewed open-access journal that focuses on general and internal medicine, pathogenesis, epidemiology, diagnosis, monitoring and treatment protocols. The journal is characterized by the rapid reporting of reviews, original research and clinical studies across all disease areas.

A key focus is the elucidation of disease processes and management protocols resulting in improved outcomes for the patient. The manuscript management system is completely online and includes a very quick and fair peer-review system. Visit http://www.dovepress.com/ testimonials.php to read real quotes from published authors.

Submit your manuscript here: http://www.dovepress.com/international-journal-of-general-medicine-journal 